\title{
A SMALL OUTBREAK OF DYSENTERY ASSOCIATED WITH AN UNUSUAL BACILLUS.
}

\author{
By J. BAMFORTH, M.D., D.P.H., \\ Assistant Bacteriologist, St Thomas's Hospital.
}

IN January, 1923, a small outbreak of dysentery occurred amongst the nursing staff of a certain institution. In all there were six cases. Only one case, the first which occurred, showed symptoms of any great severity. In the remaining five cases the symptoms were slight, and the patients were able to return to duty in seven or eight days from the commencement of the illness.

In each of these five cases the onset was marked by fever, malaise, pain in the abdomen, frequency of motions and some tenesmus. For the first 48 hours or so the temperature showed elevation to $102^{\circ} \mathrm{F}$. or $103^{\circ} \mathrm{F}$., but subsequently quickly returned to normal. At the commencement of the disease there were, on the average, five to eight motions in the 24 hours, but in two or three days this frequency ceased and the number became normal. Blood and mucus or mucus alone were present in the faeces in the early stages.

The symptoms in the first case were of greater severity. The patient had a more protracted convalescence, and did not return to duty until more than a month had elapsed. There was fever for the first week. For the first three or four days the number of stools per 24 hours was six to eight and blood and mucus was present. After this period the frequency gradually abated and the blood and mucus almost disappeared from the faeces, but there was some recurrence of this symptom during the early part of the second week, although at this period the temperature had returned to normal. The abdominal pain, a diffuse pain over the lower part of the abdomen, was a prominent feature in this case and with the tenesmus lasted considerably longer than in any of the succeeding five cases.

Reviewing the symptomatology as a whole I think that this outbreak of dysentery would appear to have shown a distinct resemblance in severity to the milder cases of Flexner dysentery, as seen in Eastern countries where dysentery occurs in epidemic form.

An investigation into the source of infection revealed nothing. The cases did not occur simultaneously, but followed one another at intervals of a few days. All the nurses who contracted the disease took their meals in the same room, but all had been working in different wards. None had been employed in the nursing of sick children. 


\section{Bacteriological Examination.}

Specimens of faeces were examined from four cases, namely from the first case with severe symptoms (No. 1) and from three of the remaining cases (Nos. 2, 3 and 4). From three of the cases, Nos. 1, 2 and 3, a similar organism was obtained.

The faeces were plated on litmus lactose agar. The lactose used was chemically pure and was unaffected by organisms of the typhoid, paratyphoid, and dysentery (Shiga and Flexner) groups.

The first specimen from case No. 1 was obtained on the third day of the disease. Blood and mucus were abundant and an almost pure culture of the organism was obtained. A second specimen ten days later was examined with negative result.

Specimens of faeces from No. 2 (blood and mucus present) and from No. 3 (mucus present, but no blood macroscopically) were also obtained early in the disease. About a dozen colonies of the organism were found in No. 2, and a large number of colonies in No. 3 on the plates at the end of 24 hours' incubation.

Two specimens of faeces were received from No. 4 at an early stage of the infection, but examination gave negative results.

The organism obtained from the first three cases was found to be a Gram negative non-motile bacillus, showing the size and shape and the long involution forms seen in many bacilli of the coli-typhoid group. The colonies on litmus lactose agar at the end of 24 hours were definitely blue and their edges were round. They were much larger than colonies of the Shiga and Flexner dysentery bacilli. At the end of 48 hours a further increase in size had occurred: the edges were becoming uneven and the blue colour intensified in their centres. The reactions of all three on carbohydrates, using 1 per cent. carbohydrate with 1 per cent. peptone, and a Lemco broth basis and 1 per cent. of 0.06 phenol red as indicator, with slight variations were similar. Acid was formed in glucose, mannite and maltose at the end of 24 hours and remained constant for a period of ten days. In saccharose acid was formed about the fourth day and in lactose about the seventh day. Though a slight preliminary acidity might occur in dulcite, this medium became definitely alkaline on the third day, a reaction which was increased at the end of ten days' incubation. Inulin and salicin were also rendered distinctly alkaline on the fourth day with an increased reaction later. No gas was formed in any of these media. Milk became acid at the end of 24 hours and more acid in 48 hours. This acidity remained unchanged. In the case of No. 1, slight clotting was observed on the ninth day, and was complete on the tenth day. No. 2 showed partial clotting on the twelfth day and complete on the thirteenth day. No. 3 showed slight clotting on the tenth day and complete clotting on the eleventh day. Examined after ten days' incubation in 1 per cent. peptone all three organisms showed only a trace of indol formation. They were non-haemolytic and produced no liquefaction of gelatin after fourteen days. 
No effects were obtained by feeding a rabbit with living cultures of the bacillus. Pieces of carrot soaked with an emulsion were given daily for one week. The animal showed no symptoms and there was no loss of weight. An examination of the serum at the end of that time failed to reveal the presence of any specific agglutinin.

Rabbits were also inoculated with increasing doses of 24 hour live agar cultures of organisms Nos. 1 and 2. No symptoms and no loss of weight were observed to occur in the animals during the period of these injections.

In the case of No. 1 six injections were given at intervals of five or six days commencing with a dose of 100 millions and concluding with 1500 millions. In testing the serum for agglutinins it was found best to employ live agar emulsions. Suspensions in Dreyer's veal broth medium, both living and formalised, did not give such satisfactory results. After this series of injections the serum of this animal was found to agglutinate all three organisms in a dilution of $1 / 2000$.

In the case of No. 2 three injections, 250,500 and 1000 millions were given, and the serum obtained agglutinated all three organisms in a dilution of $1 / 1000$.

A slight difference was found, however, by absorption experiments and this is illustrated in the following tables:

Table A.

Rabbit anti-serum prepared by immunisation with bacillus No. 1.

$\begin{array}{ccc}\begin{array}{c}\text { End point of } \\ \text { untreated serum }\end{array} & \begin{array}{c}\text { End point after } \\ \text { saturation with } \\ \text { bacillus No. 1 }\end{array} & \begin{array}{c}\text { End point after } \\ \text { saturation with } \\ \text { bacillus No. 2 }\end{array} \\ \text { On No. 1-1 in 2000 } & \text { Nil } & \text { Nil } \\ \text { On No. 2-1 in 2000 } & \text { Nil } & \text { Nil }\end{array}$

Table B.

Rabbit anti-serum prepared by immunisation with bacillus No. 2 .

$\begin{array}{ccc}\begin{array}{c}\text { End point of } \\ \text { untreated serum }\end{array} & \begin{array}{c}\text { End point after } \\ \text { saturation with } \\ \text { bacillus No. 1 }\end{array} & \begin{array}{c}\text { End point after } \\ \text { saturation with } \\ \text { bacillus No. 2 }\end{array} \\ \text { On No. 1-1 in } 1000 & \text { Nil } & \text { Nil } \\ \text { On No. 2-1 in 1000 } & 1 \text { in } 200 & \text { Nil }\end{array}$

It will be seen that saturation of anti-serum No. 2 with organism No. 1 failed to remove completely all agglutinins for organism No. 2 .

The rabbit anti-serum No. 1 was also tested against Typhoid, Shiga and Flexner antigens. In the case of Flexner two strains were used. At the end of five hours' incubation no agglutination was obtained even in a dilution of 1/25. Conversely artificial agglutinating sera of Typhoid, Shiga and Flexner were tried against a 24 hour live agar emulsion of bacillus No. 1. At the end of two hours there was no agglutination, but after five hours all the dysentery sera gave a faint trace of agglutination in a dilution of $1 / 25$ and the typhoid serum gave, in addition, a faint trace in $1 / 50$.

Journ. of Hyg. xxII 
An examination of the sera of the patients for agglutinins was made. The serum from case No. 1 was obtained 12 days after the commencement of the illness. With bacilli Nos. 1 and 2 it gave similar results namely marked agglutination in dilutions of $1 / 25$ and $1 / 50$, a trace in $1 / 100$ and a faint trace in $1 / 200$. With bacillus No. 3 there was only a trace in 1/25 and a faint trace in 1/50. The serum from case No. 2 gave with bacillus No. 2 marked agglutination in dilutions of $1 / 25$ and $1 / 50$, and a trace in $1 / 100$. With bacillus No. 1 there was only a faint trace in 1/25 and not even this was present with bacillus No. 3. The serum from case No. 3 gave no agglutination with any of the bacilli. Agglutination experiments with Shiga and Flexner antigens were negative (lowest dilution used, 1/25).

\section{Comments.}

The fact that the organisms were present in considerable numbers in the faeces of the first three cases examined (in the first case almost in pure culture), and that two of the three cases showed definite and specific agglutination, makes it appear very probable that this organism was the cause of this small dysenteric outbreak. In addition the organism was not agglutinated by any normal sera that were tried. The exact identity of the bacillus is impossible to determine with certainty. It might be that the bacillus corresponds with the organisms described under the name of $B$. coli anaerogenes-a rather loose term which might include many different organisms. From reference to the literature it appears to correspond closely with the paradysentery bacilli described by Mita as occurring especially in children but occasionally in adults. Mita describes two types of paradysentery bacilli. He states that their colonies on agar are larger than those of true dysentery bacilli, that they are non-motile, do not liquefy gelatin and do not give rise to indol formation. $\mathrm{He}$ states also that the older cultures coagulate milk in ten to fourteen days, that acid is formed slowly both in lactose and saccharose, and that whereas type 1 forms acid in maltose and dextrin after one day's incubation, in type 2 the reaction is delayed from one to two weeks. The organism appears also to resemble closely that described by Sonne and considered to be the most frequent cause of dysentery in Scandinavia. Sonne describes a bacillus with rather large colonies showing uneven irregular edges. He states also that mannite and maltose are acidified immediately, saccharose after some days, and lactose later still. There was no formation of indol. Under the title of "Another Member of the Dysentery Group" an organism was described by Duval, and it appears to show some resemblance. This bacillus, although it produced acid in lactose, failed to clot milk. The serum of the patient from which it was obtained agglutinated the organism to a titre of $1 / 400$, the FlexnerHarris bacillus to $1 / 200$ and B.typhosus to $1 / 80$. The blood of patients suffering from typhoid agglutinated the organism in dilutions of $1 / 80$ and 1/200. Rabbits inoculated with typhoid bacilli and with the organism produced common agglutinins for both cultures. In the case of the bacillus isolated from this 
small outbreak no such affinity to the typhoid and dysentery groups could, however, be demonstrated.

It would appear that, in the investigation of cases of diarrhoea and dysentery, organisms of the slow lactose fermenting type are worthy of attention. Considerable confusion exists in bacteriological literature with regard to organisms of this class. Many bacilli showing cultural characteristics with only slight differences are encountered from time to time in the examination of both faeces and urine. So far those which I have isolated have shown no serological relationship to this organism.

In conclusion I desire to thank Professor L. S. Dudgeon for much help and advice in this investigation.

\section{REFERENCES.}

Duval, C. W. (1904). Journ. Amer. Med. Assoc. XuIr. 381.

Mita. K. (1921). Journ. Infect. Diseases, xxix. 580.

Sonne, C. (1914). Kjobenh. 230 p. $8^{\circ}$.

— (1915). Centralbl. f. Bacteriol. Orig. Lxxv. 408.

- (1915). Ibid., Orig. LXxvi。 65.

(MS. received for publication 20. xI. 1923.-Ed.) 